\title{
Influência da densidade de plantas, cortes e doses de nitrogênio na produção de capim-piatã
}

\author{
Adriano Catossi TINOS ${ }^{1 *}$, Giuliani do PRADO ${ }^{1}$, Beatriz Furlan FONSECA ${ }^{1}$, \\ Jhésmila Ingridy BUENO ${ }^{1}$, Rafael Rech BRUSCAGIN ${ }^{1}$
}

\begin{abstract}
${ }^{1}$ Departamento de Engenharia Agrícola, Universidade Estadual de Maringá, Cidade Gaúcha, PR Brasil. (Orcid: *; 0000-0001-5442-7446; 0000-0003-2857-3217; 0000-0001-8233-4159; 0000-0002-7442-5357) *E-mail: actinos@uem.br (Orcid: 0000-0002-4019-1046)
\end{abstract}

Recebido em 17/06/2019; Aceito em 09/06/2020; Publicado em 31/07/2020.

\begin{abstract}
RESUMO: O Brasil apresenta numeroso rebanho bovino e as pastagens proporcionam a maneira mais prática e econômica de fornecer forragem ao rebanho. O trabalho, conduzido na Universidade Estadual de Maringá, em Cidade Gaúcha, Paraná, objetivou avaliar o efeito da densidade de plantas e de doses de nitrogênio na produção de forragem de Brachiariabrizantha cv. Piatã. $\mathrm{O}$ experimento foi implantado em delineamento experimental em blocos ao acaso em esquema fatorial 4x4x10, com três repetições. Foram avaliados: i) doses de nitrogênio $\left(0,17,33\right.$ e $50 \mathrm{~kg} \mathrm{ha}^{-1}$ corte $\left.^{-1}\right)$,aplicadas em cobertura após cada corte do pasto; ii) densidade de plantas $\left(10,20,30\right.$ e 40 plantas $\left.\mathrm{m}^{-2}\right)$ e; iii) 10 ciclos de cortes das pastagens, realizados no decorrer do experimento. As produções de matéria fresca e seca da parte aérea da pastagem foram avaliadas. Os ciclos de corte e as doses de nitrogênio influenciaram na produção de massa fresca e seca. As maiores produções de massa fresca e seca foram obtidas na densidade de 10 plantas $\mathrm{m}^{-2}$ e, as menores, na densidade de 40 plantas $\mathrm{m}^{-}$ 2. O aumento da dose de nitrogênio até $50 \mathrm{~kg} \mathrm{~N} \mathrm{ha}^{-1}$ corte $^{-1}$ proporcionou incremento na produção de massa fresca e seca de pastagem de Piatã.
\end{abstract}

Palavras chave: ciclo de corte; forragem; massa seca.

\section{Influence of plant density and nitrogen doses on capim-piatã production}

\begin{abstract}
Brazil has a large cattle herd, and pastures have offered the most practical and economical way of providing them forage. This work was carried out at the UniversidadeEstadual de Maringá, in CidadeGaúcha city, Paraná state, and it aimed to evaluate the effect of plant density and nitrogen levels on forage production of Brachiariabrizantha cv. Piatã.The experiment was set out in a randomized complete block design in a $4 \times 4 \times 10$ factorial scheme, with three replications. The evaluated factors were: i) nitrogen doses $\left(0,17,33\right.$ e $50 \mathrm{~kg} \mathrm{ha}^{-}$ ${ }^{1}$ cut $\left.^{-1}\right)$, applied on the soil surface after each cutting cycle; ii) plant density $\left(10,20,30\right.$ e 40 plants $\left.\mathrm{m}^{-2}\right)$ and; iii) 10 pasture cutting cycles which were performed over the experiment. Fresh and dry matter productions of the pasture aerial part were evaluated. The factors cutting cycles and nitrogen levels had influenced on fresh and dry matter production of pasture. The highest yields of fresh and dry matter production were obtained at a plant density of 10 plants $\mathrm{m}^{-2}$ and the smallest yields for the plant density of 40 plants $\mathrm{m}^{-2}$. Increasing the nitrogen dose by $50 \mathrm{~kg} \mathrm{~N} \mathrm{ha}^{-1} \mathrm{cut}^{-1}$ provided an increase in the fresh and dry matter production of Brachiariabrizantha cv. Piatã.
\end{abstract}

Key words: cuttingcycle; forage; dry matter.

\section{INTRODUÇÃO}

O Brasil possui numeroso rebanho de bovinos, tanto de leite como de corte e na maioria dos estabelecimentos rurais, onde a prática da pecuária é executada de maneira extensiva. A base alimentar na criação de bovinos é constituída pelas pastagens (HOFFMANN et al., 2014), que proporciona a forma mais econômica de produzir ruminantes, como os bovinos (PORTO et al., 2017) e cobrem vastas áreas, sendo estimada em cerca de 158milhões de hectares em 2017 (IBGE, 2018).

A baixa disponibilidade de nutrientes no solo é um dos principais fatores que afetam a quantidade e a qualidade da forragem (FAGUNDES et al., 2005a). Dessa forma, a aplicação de fertilizantes no solo, de forma correta, é essencial para aumentar a produção de forragem. Uma causa para a degradação de pastagens cultivadas é a falta de adubação e consequente esgotamento da fertilidade do solo (COSTA et al., 2010). O nitrogênio (N) é um dos nutrientes mais limitantes ao crescimento (CORREA FILHO et al., 2017) e um dos mais exigidos pelas plantas forrageiras. Dentre os nutrientes que constituem a adubação, o nitrogênio apresenta destaque para a fertilização de pastagens, pois, proporciona aumento na capacidade suporte (FAGUNDES et al., 2011) e aumenta o acúmulo de forragem (FAGUNDES et al., 2005a,b; SILVA, 2015). Dessa forma, espera-se com a adubação nitrogenada acréscimo na massa de forragem e conhecer qual a melhor dose de nitrogênio é importante para alcançar o máximo potencial produtivo da Urochloa (Syn. Brachiaria)brizantha e também para reduzir custos, evitando gastos desnecessários com adubação em excesso, tendo em vista que a adubação nitrogenada é onerosa (CABRAL et al., 2016). 
Não obstante, a densidade de plantas é um ponto importante na formação das pastagens. Apesar da capacidade de perfilhamento da Brachiaria, a pastagem formada com densidade de plantas abaixo do ideal pode, entre outros aspectos, favorecer a infestação de plantas daninhas e acarretar menor lotação animal devido à menor produção de forragem. No entanto, a elevada densidade de plantas pode aumentar os custos de implantação. Portanto, a produção de forragem pode ser afetada pela variação na densidade de plantas, seja no volume produzido ou nos custos de implantação. Segundo Mata et al. (2014), o aumento na densidade de semeadura reduziu o número de perfilhos da Urochloa (Syn. Brachiaria), diminuindo gradualmente com o incremento da densidade de semeadura. Porém, a produção de matéria seca e a altura de plantas da cultivar BRS Piatã não foram afetadas pela densidade de semeadura.

Além da resposta das forrageiras submetidas à adubação nitrogenada, deve-se considerar ainda a influência da estacionalidade climática sobre as plantas forrageiras, principalmente nas regiões de clima tropical e subtropical do Brasil (FAGUNDES et al., 2006).

O conhecimento de doses de nitrogênio na adubação das pastagens, bem como a densidade de plantas e a estacionalidade climática e a interação entre estes fatores que reflitam na melhor produção de forragem é fundamental para o manejo de bovinos. Dessa forma, este trabalho teve por objetivo avaliar o efeito de doses de nitrogênio, da densidade de plantas e de ciclos de corte na produção de matéria fresca e seca ao longo do tempo da Urochloa (Syn. Brachiaria) brizantha cv. Piatã.

\section{MATERIAL E MÉTODOS}

O experimento foi conduzido no Campus do Arenito da Universidade Estadual de Maringá - UEM, no município de Cidade Gaúcha - PR, latitude 2321'31" S e longitude 5255'56" O. O clima da região é classificado como subtropical úmido mesotérmico, com temperaturas médias anuais variando de 15 a $28^{\circ} \mathrm{C}$, segundo a classificação de Köppen. A precipitação média anual na região varia de 1300 a $1400 \mathrm{~mm}$ e o solo é classificado como Latossolo Vermelho Distrófico (SANTOS et al., 2013) de textura arenosa.

Anteriormente ao experimento, a área não era cultivada a quatro anos, durante esse período foram realizadas operações de gradagem para eliminar plantas daninhas em intervalos que variavam de três a quatro meses. Para a instalação do experimento, o preparo foi realizado por uma gradagem com grade intermediária e uma gradagem de nivelamento.

O local de implantação do experimento possui dimensões de $30 \mathrm{x} 40 \mathrm{~m}\left(1200 \mathrm{~m}^{2}\right)$ e antes do preparo do solo na área de implantação do experimento foi realizada a coleta de cinco amostras simples para compor uma amostra composta de solo e posteriormente a análise química do (Tabela 1).

Com base na análise do solo, foi realizada a adubação de base com 19,99 $\mathrm{kg} \mathrm{ha}^{-1} \mathrm{~K}_{2} \mathrm{O}$ tendo como fonte o cloreto de potássio e $10 \mathrm{~kg} \mathrm{ha}^{-1}$ de $\mathrm{P}_{2} \mathrm{O}_{5}$ tendo como fonte o super fosfato simples, segundo recomendação agronômica (RAIJ et al., 1996). Os fertilizantes da adubação de base foram diluídos em água e aplicados manualmente com auxílio de regador nas unidades experimentais antes do transplantio das mudas. Em cada uma das unidades experimentais foi aplicada a quantidade de adubo necessária diluída em 3L de água.

Tabela 1. Resultado da análise química do solo antes da implantação do experimento.

Table 1. Result of soil chemical analysis before set up the experiment.

\begin{tabular}{|c|c|c|c|c|c|c|c|c|c|c|c|}
\hline $\mathrm{pH}$ & & & $\mathrm{P}$ & $\mathrm{K}^{+}$ & $\mathrm{Ca}^{+2}$ & $\mathrm{Mg}^{+2}$ & SB & CTC & $(\mathrm{Al}+\mathrm{H})$ & $\mathrm{V}$ & M.O. \\
\hline $\mathrm{H}_{2} \mathrm{O}$ & $\mathrm{CaCl}_{2}$ & SMP & $\mathrm{mg} \mathrm{dm}^{-3}$ & & 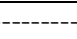 & ------- & $\mathrm{l}_{\mathrm{c}} \mathrm{dm}$ & & 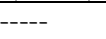 & - ---- & ------ \\
\hline 6,0 & 5,0 & 7,35 & 20,8 & 0,14 & 1,20 & 0,43 & 1,8 & 3,6 & 1,8 & 49,2 & 0,7 \\
\hline
\end{tabular}

$\mathrm{P}=$ Fósforo; $\mathrm{K}^{+}=$Potássio; $\mathrm{Ca}^{+2}=$ Cálcio; $\mathrm{Mg}^{+2}=$ Magnésio; $\mathrm{SB}=$ Soma de bases; CTC = Capacidade de troca catiônica; $\mathrm{V}=$ Saturação por bases; M.O.

= Matéria orgânica: DS = Densidade do solo

O delineamento experimental utilizado foi em blocos ao acaso em esquema fatorial $4 \times 4 \times 10$ com três repetições, sendo quatro doses de $\mathrm{N}\left(0,17,33\right.$ e $50 \mathrm{~kg} \mathrm{~N} \mathrm{ha}^{-1}$ corte1)realizada em cobertura após cada corte do pasto, densidade de plantas $\left(10,20,30\right.$ e 40 plantas $\left.\mathrm{m}^{-2}\right)$ e, cortes das pastagens realizados no decorrer do experimento. As doses de $\mathrm{N}$ foram determinadas com base nas doses utilizadas por Canto et al. (2013) em capim-tanzânia, sendo a fonte de N utilizada a ureia ( $45 \%$ de N).Para o segundo fator, densidade de plantas, as densidades correspondem a 50, 100, 150 e 200\%, respectivamente da recomendação de Dias Filho (2012), que estabelece 20 plantas $\mathrm{m}^{-2}$ para o gênero Brachiaria. O terceiro fator se refere à variação temporal, que são os cortes realizados no decorrer do experimento.

A implantação do experimento foi realizada por meio de mudas (Figura 1a), nos dias 12 e 13 de setembro de 2014, sendo as mudas cultivadas no viveiro florestal de mudas do Campus do Arenito - UEM. Para a obtenção das mudas, foram semeadas três sementes de Urochloa (Syn. Brachiaria) brizantha cv. Piatã em cada tubete em viveiro florestal, nos dias 14 e 15 de agosto de 2014, posteriormente foi realizado o desbaste, sendo em cada tubete deixada apenas uma muda, a mais vigorosa. Essas mudas foram transplantadas manualmente e distribuídas espacialmente em formato triangular dentro das parcelas experimentais (Figura 1b), buscando atender a densidade definida para cada nível do fator densidade de plantas e também ocupar de maneira uniforme a área da parcela (Tabela 2).

Tabela 2. Distribuição espacial de plantas nas parcelas de 2 × 3 m (6 $\left.\mathrm{m}^{2}\right)$ para o fator densidade populacional.

Table 2. Spatial distribution of plants in the $2 \times 3 \mathrm{~m}\left(6 \mathrm{~m}^{2}\right)$ plots for the population density factor.

\begin{tabular}{lcccc}
\hline \multirow{2}{*}{ Variável } & \multicolumn{4}{c}{ Plantas por $\mathrm{m}^{2}$} \\
\cline { 2 - 5 } & 10 & 20 & 30 & 40 \\
\hline Número de linhas & 6 & 10 & 12 & 14 \\
Espaçamento na entre linha $(\mathrm{m})$ & 0,33 & 0,20 & 0,167 & 0,143 \\
Número de plantas na linha & 10 & 12 & 15 & 17 \\
Espaçamento na linha (m) & 0,30 & 0,25 & 0,200 & 0,175 \\
Total de plantas na parcela & 60 & 120 & 180 & 240 \\
\hline
\end{tabular}


Tinos et al.

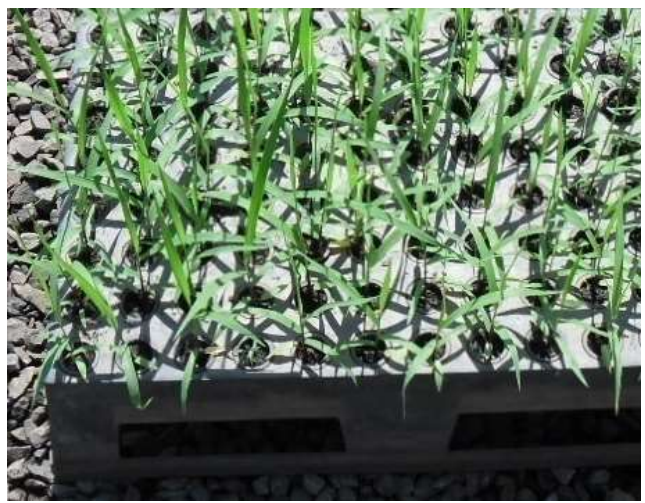

(a)

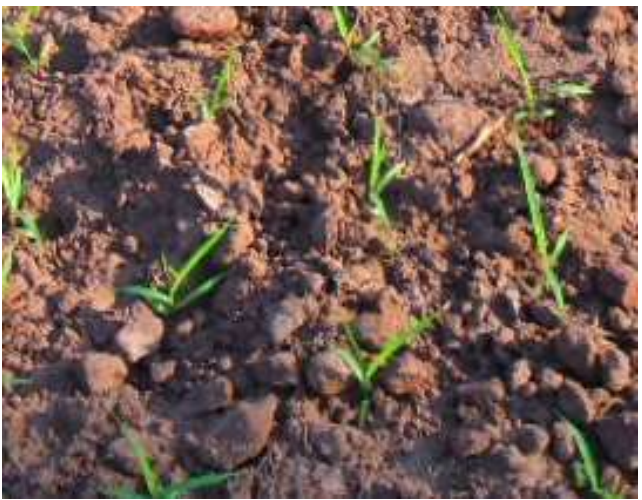

(b)

Figura 1. Mudas da pastagem empregadas (a) e disposição triangular na parcela (b).

Figure 1. Pasture seedlings employed (a) and triangular arrangement in the plot (b).

A pastagem foi cortada em intervalos que variaram em função do clima, pois em períodos mais quentes o desenvolvimento da pastagem é mais rápido em comparação com períodos mais frios. Dessa forma, os cortes foram realizados quando a pastagem atingiu altura mínima de $0,5 \mathrm{~m}$. No total, foram realizados dez cortes, o primeiro 63 dias após as mudas serem transplantadas e o intervalo entre o primeiro e o último corte foi de 545 dias. Após cada corte, foi aplicada a dose de nitrogênio na forma de ureia em cobertura, correspondente a cada tratamento, esta dose foi diluída em três litros de água, com o intuito de aplicar uniformemente o fertilizante na parcela, e aplicada no mesmo dia em que foi realizado o corte, manualmente com auxílio de regador. Quanto a forma de aplicação do fertilizante, Almeida et al. (2011) afirmam que a eficiência do fertilizante nitrogenado é aumentada quando este é aplicado via fertirrigação, porém os autores não quantificam este aumento da eficiência do fertilizante.

Cada unidade experimental possuía dimensões de 2 × $3 \mathrm{~m}$ $\left(6 \mathrm{~m}^{2}\right.$ de área total). Em cada corte foi realizada uma coleta de matéria fresca por unidade experimental, no centro, com auxílio de uma moldura metálica retangular com dimensões de $1 \times 2 \mathrm{~m}\left(2 \mathrm{~m}^{2}\right)$ a uma altura de $0,30 \mathrm{~m}$, altura esta que se adéqua ao recomendado por Flores et al. (2008) que é de 0,2 a $0,4 \mathrm{~m}$ para Urochloa (Syn. Brachiaria) brizantha.

Como variáveis respostas, foram quantificadas a produção de matéria fresca e seca da pastagem. A produção de matéria fresca foi calculada utilizando a massa coletada, pesada logo após o corte em balança de precisão e a área de coleta, estimando para um hectare. Não foi quantificado o teor de água da pastagem nos diferentes cortes. Para a obtenção da matéria seca, a massa fresca de forragem foi dividida em duas, três, ou quatro partes, dependendo do seu volume e seca em estufa com renovação e circulação de ar forçada a $65^{\circ} \mathrm{C}$ por $72 \mathrm{~h}$ sendo posteriormente pesadas em balança de precisão. Como o intervalo entre cortes não foi o mesmo para todos os cortes realizados, a produção de matéria fresca e seca foi calculada e expressa em $\mathrm{kg} \mathrm{ha}^{-1}$ dia $^{-}$ ${ }^{1}$ para ser possível comparar a produção entre os cortes realizados.

Os dados foram submetidos à análise estatística com auxílio do software Sisvar 5.4, através do teste F ao nível de $5 \%$ de significância e nos casos significativos, os dados foram submetidos ao teste de médias de Tukey ao nível de 5\% de probabilidade de erro. Adicionalmente foi realizada análise de regressão para verificar o efeito em resposta às doses de $\mathrm{N}$ e das densidades de plantas estudadas.

\section{RESULTADOS}

As produções de massa fresca e seca da forrageira Urochloa (Syn. Brachiaria) brizantha cv. Piatã foram influenciadas pelas densidades de plantas e pelas doses de nitrogênio (Tabela 3). O efeito dos cortes foi significativo tanto para a produção de massa fresca quanto para a produção de massa seca, o mesmo ocorreu com a interação entre densidade de plantas e cortes, assim como para a interação doses de nitrogênio e corte.

Tabela 3. Análise de variância para produção de massa fresca e seca $\left(\mathrm{kg} \mathrm{ha}^{-1} \mathrm{dia}^{-1}\right)$.

Table 3. Analysis of variance for fresh and dry mass production $\left(\mathrm{kg} \mathrm{ha}^{-1} \mathrm{day}^{-1}\right)$.

\begin{tabular}{|c|c|c|c|c|}
\hline \multirow{2}{*}{ F.V. } & \multicolumn{2}{|c|}{----Massa Fresca---- } & \multicolumn{2}{|c|}{---Massa seca--- } \\
\hline & G.L & S.Q. & G.L & S.Q. \\
\hline Bloco & 2 & $1030,62^{\text {ns }}$ & 2 & $29463,92 \mathrm{~ns}$ \\
\hline Densidade & 3 & $3733,85^{* *}$ & 3 & $77218,74 * *$ \\
\hline Nitrogênio & 3 & $20613,86 * *$ & 3 & $408996,12^{* *}$ \\
\hline Densidade x Nitrogênio & 9 & $1938,75^{\mathrm{ns}}$ & 9 & $39812,31 \mathrm{~ns}$ \\
\hline Erro 1 & 30 & 5750,29 & 30 & 151580,55 \\
\hline Corte & 9 & $806621,21 * *$ & 9 & $16985291,74^{* *}$ \\
\hline Densidade x Corte & 27 & $12358,58^{* *}$ & 27 & $222380,48^{* *}$ \\
\hline Nitrogênio x Corte & 27 & $28777,38 * *$ & 27 & $522863,74^{* *}$ \\
\hline Densidade x Nitrogênio x Corte & 81 & $11546,07 \mathrm{~ns}$ & 81 & $251821,39 \mathrm{~ns}$ \\
\hline Erro 2 & 288 & 70507,99 & 288 & 1223389 \\
\hline Total & 479 & 962878,63 & 479 & 19912819,02 \\
\hline CV $1(\%)$ & 21,52 & & 26,08 & \\
\hline CV $2(\%)$ & 24,32 & & 23,92 & \\
\hline Média & 64,33 & & 272,51 & \\
\hline
\end{tabular}


F.V.: Fontes de Variação; G.L.: Graus de Liberdade; S.Q.: Soma de Quadrados; CV: Coeficiente de Variação.

Na Figura 2 são apresentadas as médias de produção de massa seca e fresca em função da densidade de plantas e das doses de nitrogênio aplicadas.

A Tabela 4 apresenta as médias de produção de massa fresca e massa seca para os dez cortes realizados no decorrer do experimento bem como a data de realização destes.

Na Figura 3 são apresentados os dados de variação da radiação solar incidente, temperatura do ar média e da precipitação no período de condução do experimento.

As médias da produção de massa fresca e massa seca de cada densidade de plantas e para cada corte são apresentadas na Tabela 5.
Como mostrado na Tabela 5, o segundo corte foi o que apresentou maior média de produção de massa fresca e seca, respectivamente, para todas as densidades de plantas estudadas. Por outro lado, nos cortes 6 e 7, foi observado que a produção de massa seca foi a mais baixa estatisticamente para todas as densidades de plantas estudadas.

Observa-se que no corte 2, tanto para massa fresca quanto para massa seca, a produção foi maior estatisticamente que os demais cortes. Por outro lado, as médias menores estatisticamente foram observadas nos cortes 6 e 7 . Comportamento semelhante ao observado no efeito da densidade de plantas na mesma variável analisada (Tabela 6).
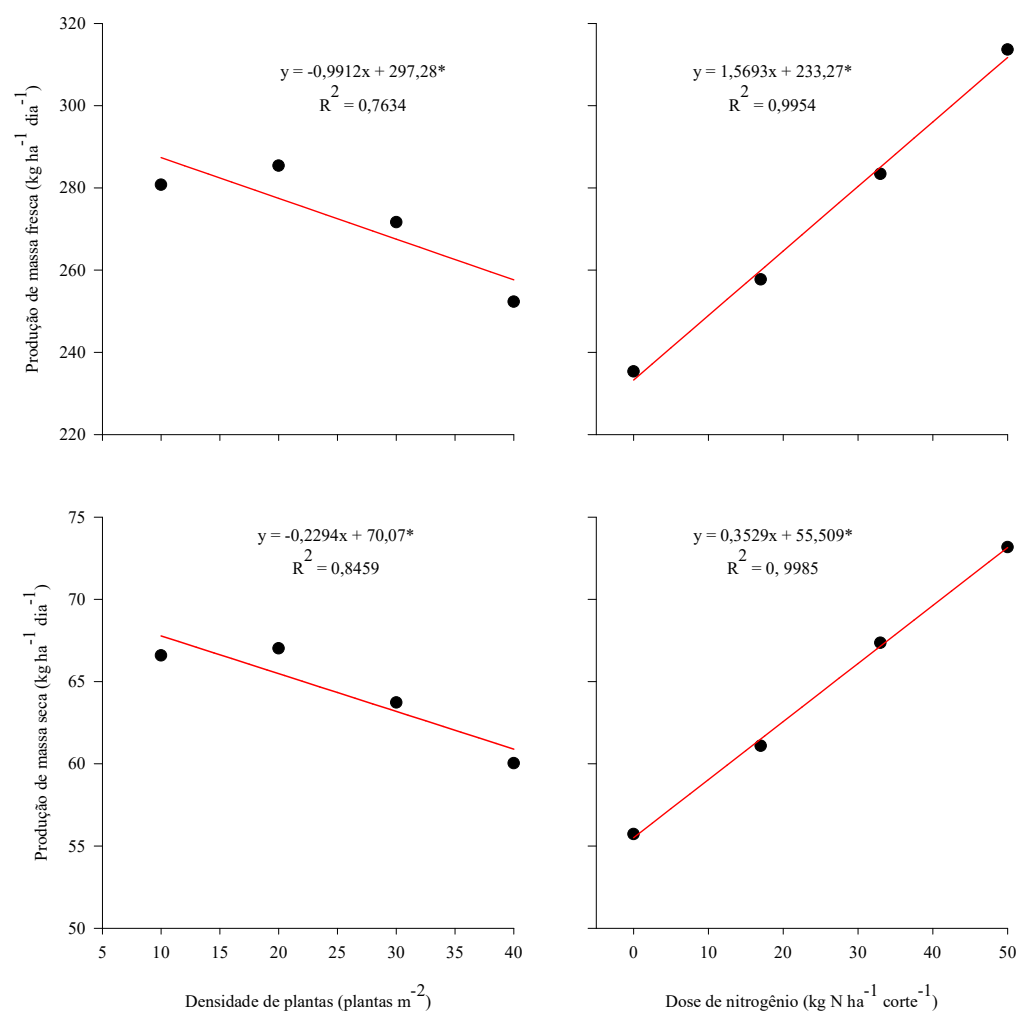

Figura 2. Médias da produção de massa fresca em função das densidades de plantas e das doses de nitrogênio avaliadas.

Figure 2. Average fresh mass production as a function of plant densities and nitrogen doses evaluated.

Tabela 4. Médias da produção de massa fresco e massa seca em cada corte e data de realização dos cortes.

Table 4. Average of fresh and dry mass production in each cut and cut dates.

\begin{tabular}{cccc}
\hline Cortes & Data do corte & Massa fresca $\left(\mathrm{kg} \mathrm{ha}^{-1} \mathrm{dia}^{-1}\right)$ & ${\text { Massa seca }\left(\mathrm{kg} \mathrm{ha}^{-1} \mathrm{dia}^{-1}\right)}^{-16,56 \mathrm{D}}$ \\
\hline 1 & $14 / 11 / 14$ & $218,83 \mathrm{D} *$ & $162,46 \mathrm{~A}$ \\
2 & $17 / 12 / 14$ & $740,53 \mathrm{~A}$ & $95,57 \mathrm{~B}$ \\
3 & $22 / 01 / 15$ & $408,44 \mathrm{~B}$ & $75,04 \mathrm{C}$ \\
4 & $05 / 03 / 15$ & $331,47 \mathrm{C}$ & $46,85 \mathrm{D}$ \\
5 & $17 \mathrm{e} 19 / 04 / 15$ & $183,04 \mathrm{DE}$ & $17,68 \mathrm{E}$ \\
6 & $09 / 06 / 15$ & $70,26 \mathrm{~F}$ & $12,11 \mathrm{E}$ \\
7 & $02 \mathrm{e} 03 / 09 / 15$ & $68,38 \mathrm{~F}$ & $49,58 \mathrm{D}$ \\
8 & $12 / 11 / 15$ & $167,23 \mathrm{E}$ & $81,62 \mathrm{C}$ \\
9 & $07 / 01 / 16$ & $332,83 \mathrm{C}$ & $53,85 \mathrm{D}$ \\
\hline
\end{tabular}

*Médias seguidas da mesma letra maiúscula na coluna não diferem entre si pelo teste de Tukey a $5 \%$ de probabilidade.

A Figura 4 apresenta os valores das produções de massa fresca e seca para todos os cortes em função das densidades de plantas estudadas. Nessa figura, observa-se que para a produção de massa fresca apenas os cortes 1,3 e 4 apresentaram diferença estatística significativa entre as densidades de plantas estudadas, sendo que no corte 1 o incremento na densidade de plantas proporcionou elevação na quantidade de massa fresca de forma linear. Entretanto, 
Tinos et al.

nos cortes 3 e 4, o incremento na densidade de plantas ocasionou a redução de forma linear na quantidade de massa fresca produzida. Sobretudo no corte 3 , onde essa redução foi mais expressiva, decaindo de 465,2 para $317 \mathrm{~kg} \mathrm{ha}^{-1} \mathrm{dia}^{-1}$ para as densidades de 10 e 40 plantas $\mathrm{m}^{-2}$, respectivamente, redução de $31,8 \%$ na quantidade de forragem produzida.

Como observado na Figura 5, nos cortes 1, 3, 5, 8, 9 e 10 as doses de nitrogênio estudadas influenciaram de forma significativa a produção de massa fresca, sendo linearmente positiva a relação entre essas variáveis (Tabela 7). O ganho de produção de massa fresca mais acentuado foi obtido no corte 9, em que ocorreu ganho na produção diária de massa fresca de $165 \%$ na comparação entre a dose $0\left(180,6 \mathrm{~kg} \mathrm{ha}^{-1} \mathrm{dia}^{-1}\right)$ e $50 \mathrm{~kg} \mathrm{~N} \mathrm{ha}{ }^{-1}$ corte $^{-1}\left(479,2 \mathrm{~kg} \mathrm{ha}^{-1} \mathrm{dia}^{-1}\right)$.

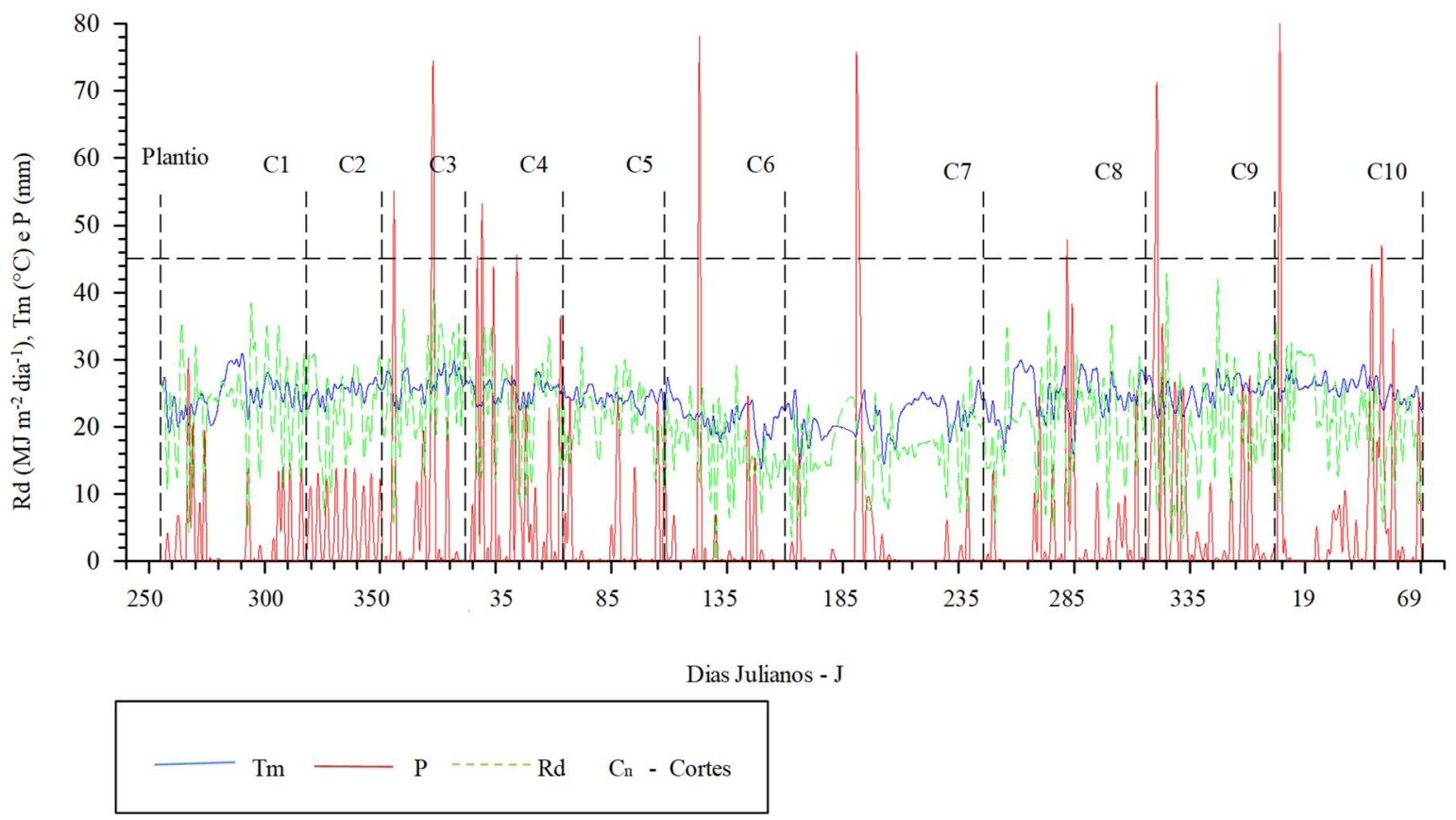

Figura 3. Variação da radiação solar incidente (Rd), temperatura do ar média $(\mathrm{Tm})$ e precipitação $(\mathrm{P})$ no período de condução do experimento.

Figure 3. Variation of incident solar radiation (Rd), mean air temperature (Tm) and rainfall (P) along the experiment.

Tabela 5. Médias da produção de massa fresca e seca $\left(\mathrm{kg} \mathrm{ha}^{-1} \mathrm{dia}^{-1}\right)$ para cada corte e densidade de plantas.

Table 5. Averages of fresh and dry mass production $\left(\mathrm{kg} \mathrm{ha}^{-1} \mathrm{day}^{-1}\right)$ for each cut and plant density.

\begin{tabular}{|c|c|c|c|c|}
\hline \multirow{2}{*}{ Cortes } & \multicolumn{4}{|c|}{ Densidade (plantas $\mathrm{m}^{-2}$ ) } \\
\hline & 10 & 20 & 30 & 40 \\
\hline \multicolumn{5}{|c|}{ Massa fresca $\left(\mathrm{kg} \mathrm{ha}^{-1} \mathrm{dia}^{-1}\right)$} \\
\hline 1 & $169,44 \mathrm{D} *$ & $229,29 \mathrm{D}$ & $236,77 \mathrm{C}$ & $239,81 \mathrm{BC}$ \\
\hline 2 & $761,48 \mathrm{~A}$ & $755,42 \mathrm{~A}$ & $703,28 \mathrm{~A}$ & $741,91 \mathrm{~A}$ \\
\hline 3 & $465,27 \mathrm{~B}$ & $452,43 \mathrm{~B}$ & $399,07 \mathrm{~B}$ & $317,01 \mathrm{~B}$ \\
\hline 4 & $357,73 \mathrm{C}$ & $352,87 \mathrm{C}$ & $325,89 \mathrm{~B}$ & $289,38 \mathrm{~B}$ \\
\hline 5 & $196,40 \mathrm{D}$ & $192,42 \mathrm{D}$ & $182,48 \mathrm{C}$ & $160,89 \mathrm{DC}$ \\
\hline 6 & $69,79 \mathrm{E}$ & $74,91 \mathrm{E}$ & $71,03 \mathrm{D}$ & $65,30 \mathrm{E}$ \\
\hline 7 & $67,78 \mathrm{E}$ & $68,26 \mathrm{E}$ & 69,67D & $67,82 \mathrm{E}$ \\
\hline 8 & $183,69 \mathrm{D}$ & $171,60 \mathrm{D}$ & $171,66 \mathrm{C}$ & $141,96 \mathrm{DE}$ \\
\hline 9 & $329,31 \mathrm{C}$ & $349,25 \mathrm{C}$ & $344,56 \mathrm{~B}$ & $308,18 \mathrm{~B}$ \\
\hline 10 & $206,38 \mathrm{D}$ & $207,48 \mathrm{D}$ & $211,84 \mathrm{C}$ & $190,55 \mathrm{CD}$ \\
\hline \multicolumn{5}{|c|}{ Massa seca $\left(\mathrm{kg} \mathrm{ha}^{-1} \mathrm{dia}^{-1}\right)$} \\
\hline 1 & $38,49 \mathrm{D}$ & 49,14D & $53,17 \mathrm{D}$ & $53,43 \mathrm{CD}$ \\
\hline 2 & $168,43 \mathrm{~A}$ & $165,40 \mathrm{~A}$ & $152,14 \mathrm{~A}$ & $163,88 \mathrm{~A}$ \\
\hline 3 & $109,49 \mathrm{~B}$ & 106,01B & $92,59 \mathrm{~B}$ & $74,18 \mathrm{~B}$ \\
\hline 4 & $80,35 \mathrm{C}$ & $78,76 \mathrm{C}$ & $73,61 \mathrm{BC}$ & $67,46 \mathrm{BC}$ \\
\hline 5 & $49,24 \mathrm{D}$ & $49,90 \mathrm{D}$ & $45,35 \mathrm{D}$ & $42,89 \mathrm{D}$ \\
\hline 6 & $17,78 \mathrm{E}$ & $18,10 \mathrm{E}$ & $17,94 \mathrm{E}$ & $16,90 \mathrm{E}$ \\
\hline 7 & $12,30 \mathrm{E}$ & $12,01 \mathrm{E}$ & $12,20 \mathrm{E}$ & $11,91 \mathrm{E}$ \\
\hline 8 & $53,81 \mathrm{D}$ & $50,95 \mathrm{D}$ & $50,96 \mathrm{D}$ & $42,61 \mathrm{D}$ \\
\hline 9 & $80,78 \mathrm{C}$ & $85,32 \mathrm{C}$ & $84,59 \mathrm{~B}$ & $75,79 \mathrm{~B}$ \\
\hline 10 & $55,12 \mathrm{D}$ & $54,47 \mathrm{D}$ & $54,62 \mathrm{CD}$ & $51,19 \mathrm{CD}$ \\
\hline
\end{tabular}


Influência da densidade de plantas, cortes e doses de nitrogênio na produção de capim-piatã

Tabela 6. Médias da produção de massa fresca e seca $\left(\mathrm{kg} \mathrm{ha}^{-1} \mathrm{dia}^{-1}\right)$ para cada corte e doses de nitrogênio.

Table 6. Averages of fresh and dry mass production $\left(\mathrm{kg} \mathrm{ha}^{-1} \mathrm{day}^{-1}\right)$ for each cut and nitrogen doses.

\begin{tabular}{|c|c|c|c|c|}
\hline \multirow{2}{*}{ Cortes } & \multicolumn{4}{|c|}{ Dose de nitrogênio $\left(\mathrm{kg} \mathrm{N} \mathrm{ha}^{-1}\right.$ corte $\left.^{-1}\right)$} \\
\hline & 0 & 17 & 33 & 50 \\
\hline \multicolumn{5}{|c|}{ Massa fresca $\left(\mathrm{kg} \mathrm{ha}^{-1} \mathrm{dia}^{-1}\right)$} \\
\hline 1 & $190,07 C^{*}$ & $185,71 \mathrm{D}$ & $232,14 \mathrm{D}$ & $267,39 \mathrm{D}$ \\
\hline 2 & $777,52 \mathrm{~A}$ & $713,25 \mathrm{~A}$ & $723,48 \mathrm{~A}$ & $747,85 \mathrm{~A}$ \\
\hline 3 & $358,79 \mathrm{~B}$ & $430,67 \mathrm{~B}$ & $417,36 \mathrm{~B}$ & $426,96 \mathrm{BC}$ \\
\hline 4 & $321,82 \mathrm{~B}$ & $323,01 \mathrm{C}$ & $318,94 \mathrm{C}$ & $362,10 \mathrm{C}$ \\
\hline 5 & $137,21 \mathrm{C}$ & $182,57 \mathrm{D}$ & $193,93 \mathrm{D}$ & $218,46 \mathrm{D}$ \\
\hline 6 & $50,76 \mathrm{DE}$ & $63,98 \mathrm{E}$ & $79,92 \mathrm{E}$ & $86,37 \mathrm{E}$ \\
\hline 7 & $44,33 \mathrm{E}$ & $72,28 \mathrm{E}$ & $67,73 \mathrm{E}$ & $89,19 \mathrm{E}$ \\
\hline 8 & $133,51 \mathrm{CD}$ & $146,19 \mathrm{DE}$ & 178,57D & $210,65 \mathrm{D}$ \\
\hline 9 & $180,65 \mathrm{C}$ & $272,47 \mathrm{C}$ & $398,95 \mathrm{BC}$ & $479,24 \mathrm{~B}$ \\
\hline 10 & $158,59 \mathrm{C}$ & $187,10 \mathrm{D}$ & $222,72 \mathrm{D}$ & $247,85 \mathrm{D}$ \\
\hline \multicolumn{5}{|c|}{ Massa seca $\left(\mathrm{kg} \mathrm{ha}^{-1} \mathrm{dia}^{-1}\right)$} \\
\hline 1 & $41,93 \mathrm{C}$ & $41,73 \mathrm{E}$ & $52,11 \mathrm{CD}$ & $58,46 \mathrm{E}$ \\
\hline 2 & $172,22 \mathrm{~A}$ & $157,07 \mathrm{~A}$ & $158,96 \mathrm{~A}$ & $161,61 \mathrm{~A}$ \\
\hline 3 & $84,49 B$ & $100,81 \mathrm{~B}$ & $98,61 \mathrm{~B}$ & $98,37 \mathrm{BC}$ \\
\hline 4 & $71,23 \mathrm{~B}$ & $74,00 \mathrm{C}$ & $72,22 \mathrm{C}$ & $82,73 \mathrm{CD}$ \\
\hline 5 & $36,64 \mathrm{C}$ & $47,15 \mathrm{E}$ & $49,05 \mathrm{D}$ & $54,54 \mathrm{E}$ \\
\hline 6 & $13,46 \mathrm{D}$ & $16,18 \mathrm{~F}$ & $20,27 \mathrm{E}$ & $20,83 \mathrm{~F}$ \\
\hline 7 & $8,33 \mathrm{D}$ & $12,16 \mathrm{~F}$ & $12,35 \mathrm{E}$ & $15,60 \mathrm{~F}$ \\
\hline 8 & $40,26 \mathrm{C}$ & $43,72 \mathrm{E}$ & $52,77 \mathrm{CD}$ & $61,57 \mathrm{E}$ \\
\hline 9 & $46,51 \mathrm{C}$ & $67,90 \mathrm{CD}$ & $97,98 \mathrm{~B}$ & $114,08 \mathrm{~B}$ \\
\hline 10 & $42,18 \mathrm{C}$ & $50,18 \mathrm{DE}$ & $59,16 \mathrm{CD}$ & $63,89 \mathrm{DE}$ \\
\hline
\end{tabular}

*Médias seguidas da mesma letra maiúscula na coluna não diferem entre si pelo teste de Tukey a $5 \%$ de significância.

$$
\begin{aligned}
& \text { Corte } 1: y=2,185 x+164,1 * R^{2}=0,721 \\
& \text { Corte 3: } y=-4,981 x+532,9^{*} R^{2}=0,911 \\
& \text { Corte 4: } y=-2,320 x+384,4 * R^{2}=0,912
\end{aligned}
$$
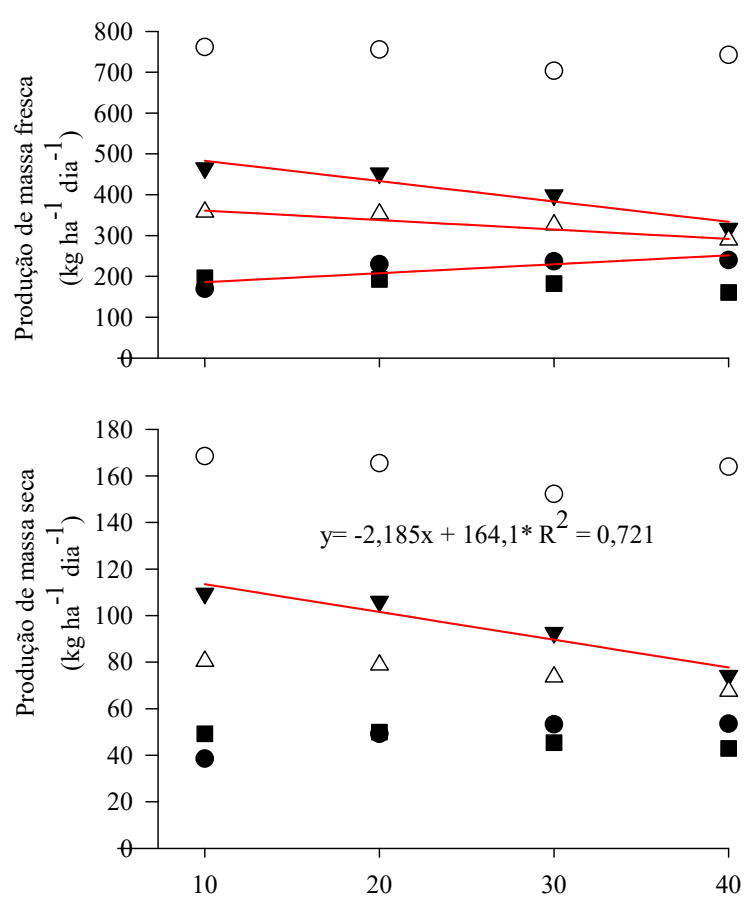
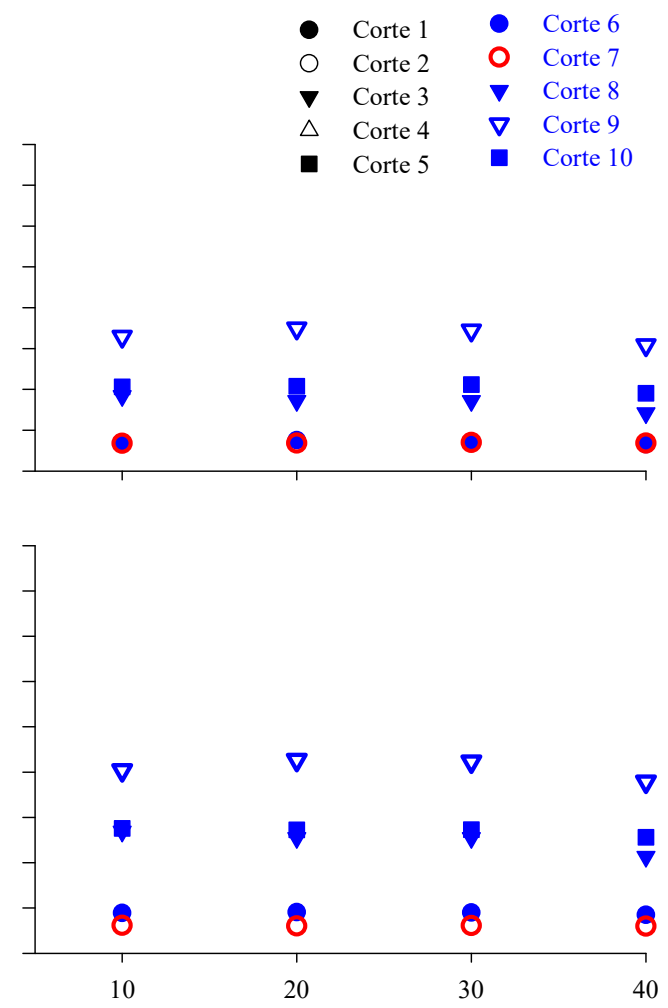

Densidade de plantas (plantas $\mathrm{m}^{-2}$ )

Figura 4. Produção de massa fresca e seca para as densidades de plantas avaliadas.

Figure 4. Production of fresh mass and dry mass for the plant density evaluated. 

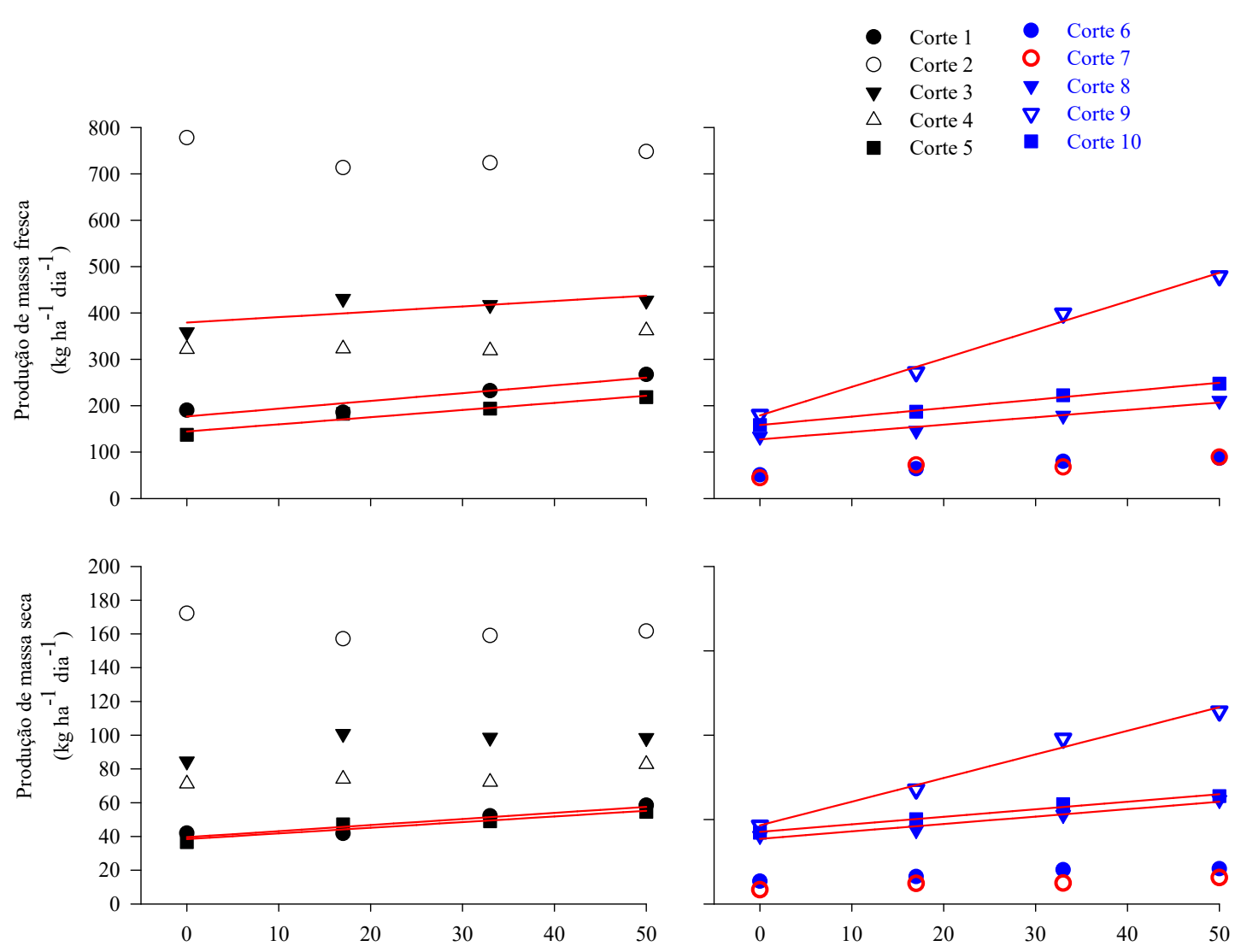

Dose de nitrogênio $\left(\mathrm{kg} \mathrm{N} \mathrm{ha}^{-1}\right.$ corte $\left.^{-1}\right)$

Figura 5. Produção de massa fresca e massa seca para as doses de nitrogênio avaliadas.

Figure 5. Production of fresh mass and dry mass for the nitrogen doses evaluated.

Tabela 7. Equações de regressão e coeficiente de determinação $\left(\mathrm{R}^{2}\right)$ para a interação entre a produção de massa fresca e seca e as doses de nitrogênio.

Table 7. Regression equations and coefficients of determination $\left(\mathrm{R}^{2}\right)$ for the interaction between fresh and dry mass production and nitrogen doses.

\begin{tabular}{ccccc}
\hline Cortes & \multicolumn{3}{c}{ Massa fresca } & \multicolumn{2}{c}{ Massa seca } \\
\hline & Equação & Coeficiente de determinação $\left(\mathrm{R}^{2}\right)$ & Equação & Coeficiente de determinação $\left(\mathrm{R}^{2}\right)$ \\
\hline 1 & $\mathrm{y}=1,672 \mathrm{x}+177,0$ & $\mathrm{R}^{2}=0,86$ & $\mathrm{y}=0,360 \mathrm{x}+39,55$ & $\mathrm{R}^{2}=0,88$ \\
3 & $\mathrm{y}=1,159 \mathrm{x}+379,4$ & $\mathrm{R}^{2}=0,54$ & $\mathrm{y}=0,335 \mathrm{x}+38,45$ & - \\
5 & $\mathrm{y}=1,54 \mathrm{x}+144,5$ & $\mathrm{R}^{2}=0,94$ & $\mathrm{y}=0,439 \mathrm{x}+38,61$ & $\mathrm{R}^{2}=0,92$ \\
8 & $\mathrm{y}=1,587 \mathrm{x}+127,5$ & $\mathrm{R}^{2}=0,96$ & $\mathrm{y}=1,400 \mathrm{x}+46,61$ & $\mathrm{R}^{2}=0,96$ \\
9 & $\mathrm{y}=6,151 \mathrm{x}+179,0$ & $\mathrm{R}^{2}=0,99$ & $\mathrm{y}=0,446 \mathrm{x}+42,70$ & $\mathrm{R}^{2}=0,98$ \\
10 & $\mathrm{y}=1,826 \mathrm{x}+158,4$ & $\mathrm{R}^{2}=0,99$ & & $\mathrm{R}^{2}=0,98$ \\
\hline
\end{tabular}

\section{DISCUSSÃO}

Analisando os dados como um todo (Figura 2) verificouse que a produção de massa fresca foi mais elevada para a menor densidade (10 plantas $\left.\mathrm{m}^{-2}\right)$, decrescendo linearmente com o aumento desta. Por outro lado, com o incremento na quantidade de nitrogênio aplicado $\left(\mathrm{kg} \mathrm{ha}^{-1} \mathrm{corte}^{-1}\right)$, a produção de massa fresca foi linearmente proporcional (Figura 2).

Observando os dados como um todo, verifica-se que, da mesma forma que a produção de massa fresca, a produção de massa seca foi linearmente e inversamente proporcional às densidades de plantas e linearmente proporcional às doses de nitrogênio aplicadas (Figura 2). Fagundes et al. (2005b), avaliando doses crescentes de nitrogênio em pastagens, também observaram aumento significativo na taxa de acúmulo de forragem de Urochloa (Syn. Brachiaria) decumbens com o incremento da dose de nitrogênio aplicada, assim como Quatrin et al. (2015) observaram acréscimo na massa de forragem em pré-pastejo proporcional à adubação nitrogenada.

A produção de massa fresca, assim como de massa seca, no corte 2, foi maior do que nos demais cortes (Tabela 4). Isso provavelmente ocorreu pelo fato desse corte ter sido realizado no fim da primavera, dessa forma, com temperaturas elevadas, maior radiação incidente e maior precipitação pluviométrica, comuns para a região nessa época do ano, a produção de massa fresca e seca foram favorecidas (Figura 3).

Por outro lado, nos cortes 6 e 7 (Tabela 4) foram observados os menores valores de produção de massa fresca e seca. Esses cortes foram realizados durante o inverno e como é característico dessa estação as baixas temperaturas, menor radiação incidente e baixos índices pluviométricos para a região onde o experimento foi conduzido (Figura 3), 
isso prejudicou a produção de massa fresca e seca da pastagem de B. brizantha. Observa-se também que o intervalo entre os cortes 6 e 7 foi o maior entre todos os demais, fato que também reflete o limitante de crescimento ocasionado pela temperatura no período decorrido entre esses cortes.

Avaliando o acúmulo de forragem de Urochloa (Syn. Brachiaria) decumbens, Fagundes et al. (2005b) observaram diferença significativa entre as estações do ano, obtendo maiores valores no verão e menores no inverno, sendo a produção de massa seca da forragem de 9,7 para o inverno e $67,0 \mathrm{~kg} \mathrm{ha}^{-1} \mathrm{dia}^{-1}$ para o verão. Os autores também salientaram a influência da estação do ano na produção de forragem e, sobretudo, a característica de estacionalidade da Urochloa (Syn. Brachiaria).

As baixas produções de matéria fresca e seca nos cortes 6 e 7 podem estar relacionadas com a temperatura, pois segundo Vitor et al. (2009), a estacionalidade climática afeta a maioria das espécies forrageiras, principalmente os fatores climáticos como longos períodos sem precipitação associado ao fotoperíodo reduzido e com baixas temperaturas.

Nota-se que no primeiro corte a produção de massa fresca e seca foi menor que nos cortes 2, 3 e 4 (Tabela 5), apesar de o primeiro corte ter ocorrido em época de condições climáticas propícias para o desenvolvimento da forrageira, tal produção pode ser reflexo do não perfilhamento completo das plantas.

Os resultados apresentados na Tabela 5 podem estar associados à época do ano em que os cortes foram realizados, o corte 2 foi realizado no período com condições favoráveis de temperatura, radiação incidente e precipitação, já os cortes 6 e 7 foram realizados durante o inverno, o que sugere que a produção da pastagem, tanto de massa fresca quanto de massa seca, foi influenciada negativamente pelas baixas temperaturas e índices pluviométricos característicos da estação.

A maior produção observada no corte 2 , provavelmente se deve a estacionalidade da forrageira, pois esse corte foi realizado no fim da primavera, enquanto os cortes 6 e 7 foram realizados durante o inverno. Medeiros et al. (2007) associaram diferenças na produção de massa seca de Urochloa (Syn. Brachiaria). brizantha cv. Marandu entre cortes às épocas do ano, porque, segundo os autores, cortes realizados em épocas favoráveis, como primavera e verão, com temperaturas mais elevadas e maiores índices pluviométricos favorecem o crescimento vegetativo da planta forrageira. Todavia, os autores salientaram ainda que o corte realizado na época da estiagem, baixas temperaturas e diminuição do fotoperíodo, resultou em menor produção de massa seca. $\mathrm{O}$ mesmo é relatado por Euclides et al. (2014) que afirmam que independentemente da aplicação de fertilizantes, as forrageiras tropicais não irrigadas apresentam, de maneira geral, maiores taxas de acúmulo de forragem durante o verão, acúmulo intermediário no outono e na primavera e muito baixo no inverno. Rocha et al. (2019), associaram maior taxa de aparecimento de perfilhos de $B$. brizantha ao verão, por apresentar fatores de crescimento mais abundantes como água e temperatura

$\mathrm{Na}$ literatura, são escassos trabalhos que relacionem e densidade de plantas com a produção de forragem, normalmente são estudados os efeitos do pastejo e adubações na forrageira com densidade de plantas ou densidade de semeadura constantes. Costa et al. (2013) avaliaram a produção de massa seca de milho para silagem sob três densidades de plantas diferentes e constataram que não houve variação significativa.

Observa-se ainda, na Figura 4, que apenas no corte 3 a produção de massa seca teve diferença entre as densidades de plantas estudadas, tal diferença seguiu o modelo de ajuste linear em que a densidade de 10 plantas $\mathrm{m}^{-2}$ foi a que proporcionou maior produção de massa seca, já nos demais cortes não ocorreu diferença, corroborando com o observado por Mata et al. (2014) ao observarem que o rendimento de matéria seca de plantas de Urochloa (Syn. Brachiaria). brizantha cv. BRS Piatã não foi afetado pela densidade de semeadura.

Em relação à produção de massa seca, observa-se na Figura 5 que houve diferença para essa variável em função das doses de nitrogênio estudadas nos cortes 1, 5, 8, 9 e 10, nestes casos os valores seguiram o modelo linear, proporcional às doses de nitrogênio, em que os maiores valores de massa seca foram observados na maior dose de nitrogênio estudada corroborando com Sales et al. (2013) que observaram resposta linear da Urochloa (Syn. Brachiaria) sob doses de nitrogênio via fertirrigação. $\mathrm{O}$ aumento na produção de massa seca mais acentuado, em função da adubação nitrogenada, ocorreu no corte 9 , com incremento de $145 \%$, passando de 46,5 para $114 \mathrm{~kg} \mathrm{ha}^{-1} \mathrm{dia}^{-1}$ para as dose $0 \mathrm{e}$ $50 \mathrm{~kg} \mathrm{~N} \mathrm{ha}{ }^{-1}$ corte $^{-1}$, respectivamente. Resultado semelhante a esse foi obtido por Fagundes et al. (2005b) com incremento de $110 \%$ na produção de massa seca de pastagem com adubação nitrogenada e também por Santos et al. (2008) que avaliando adubações em dois tipos de Urochloa (Syn. Brachiaria) (B. brizantha e B. decumbens), observaram acréscimo em torno de $110 \%$ na matéria fresca, comparando a ausência e a presença de adubação nitrogenada.

O mesmo foi observado por Fagundes et al. (2005a) que também obtiveram acúmulo de forragem proporcional as doses de nitrogênio aplicadas, sendo a maior dose avaliada de $300 \mathrm{~kg} \mathrm{ha}{ }^{-1}$.Já nos demais cortes a diferença na produção de massa fresca e seca não foi significativa.

\section{CONCLUSÕES}

As épocas de corte influenciaram na produção de massa fresca e seca, assim como as doses de nitrogênio.

A produção de massa fresca e seca foi maior nos cortes realizados no verão e menor nos cortes que ocorreram no inverno.

Adubação nitrogenada proporcionou maior incremento na produção de massa seca e fresca na primavera e verão.

$\mathrm{O}$ aumento da dose de nitrogênio até $50 \mathrm{~kg} \mathrm{~N}$ ha-1 corte${ }^{1}$ proporcionou incremento na produção de massa fresca e seca de pastagem de Brachiaria brizantha cv. Piatã.

A população de 40 plantas $\mathrm{m}-2$ apresentou maior produção no primeiro corte da Brachiaria brizantha cv. Piatã.

\section{REFERÊNCIAS}

ALMEIDA, A. C. S.; MINGOTI, R.; COELHO, R. D.; LOURENÇO, L. F.; Simulação do crescimento do capim Tanzânia irrigado com base na unidade fototérmica, na adubação nitrogenada e na disponibilidade hídrica do período. Acta Scientiarum Agronomy, Maringá, v. 33, $\begin{array}{llll}\text { n. } 2, \quad \text { p. 215-222, 2011. DOI: } & \text { 2 }\end{array}$ http://dx.doi.org/10.4025/actasciagron.v33i2.4901

CABRAL, C. E. A.; CABRAL, L. S.; BONFIM-SILVA, E. M.; CARVALHO, K. S.; KROTH, B. E.; CABRAL, C. H. A. Resposta da Brachiaria brizantha cv. Marandu a 
fertilizantes nitrogenados associados ao fosfato natural reativo. Comunicata Scientiae, Belo Horizonte, v. 7, n. 1, p. 66-72, 2016. DOI: http://dx.doi.org/10.14295/CS.v7i1.964

CANTO, M. W.; HOESCHL, A. R.; BONA FILHO, A.; MORAES, A.; GASPARINO, E. Características do pasto e eficiência agronômica de nitrogênio em capim-tanzânia sob pastejo contínuo, adubado com doses de nitrogênio. Ciência Rural, Santa Maria, v. 43, n. 4, p. 682-688,2013. DOI: http://dx.doi.org/10.1590/S0103 84782013000400019

CORREA FILHO, D. V. B.; CORREIA, E. C. S. S.; DOMINGUES NETO, F. J.; SANTOS, D. V.; SILVA, T. A.; MONTEIRO, R. N. F.; FONTANA, L. F. Crescimento e desenvolvimento de aveia preta em resposta à inoculação com Azospirillum brasilense e adubação nitrogenada. Colloquium Agrariae, Presidente Prudente, v. 13, n. 2, p. 01-08, 2017. DOI: http://dx.doi.org/10.5747/ca.2017.v13.n2.a155

COSTA, D. A.; DOMINGUES, F. N.; ASTOLPHI, M. Z.; MOTA, D. A.; OAIGEN, R. P.; CALONEGO, J.; MIRANDA, A. S. Influência do arranjo de plantas sobre a composição bromatológica da silagem de milho. Veterinária em foco, Canoas, v. 10, n. 2, p. 169-177, 2013.

COSTA, K. A. P.; FAQUIN, V.; OLIVEIRA, I. P. Doses e fontes de nitrogênio na recuperação de pastagens do capim-marandu. Arquivo Brasileiro de Medicina Veterinária e Zootecnia, Belo Horizonte, v. 62, n. 1, p. 192-199, 2010. DOI: http://dx.doi.org/10.1590/S010209352010000100026

DIAS FILHO, M. B. Formação e manejo de pastagens. Belém: Embrapa, 2012. 9 p. (Comunicado Técnico, 235) Disponível

em:

<https://ainfo.cnptia.embrapa.br/digital/bitstream/ite $\mathrm{m} / 68489 / 1 /$ Oriental-ComTec235.pdf $>$ Acesso em: 10/06/2014.

EUCLIDES, V. P. B.; MONTAGNER, D. B.; BARBOSA, R. A.; NANTES, N. N. Manejo do pastejo de cultivares de Brachiariabrizantha (Hochst) Stapf e de Panicummaximum]acq. Revista Ceres, Lavras, v. 61, n. sup., p. $\quad 808-818, \quad 2014 . \quad$ DOI: http:/ /dx.doi.org/10.1590/0034-737X201461000006

FAGUNDES, J. L.; FONSECA, D. M.; GOMIDE, J. A.; NASCIMENTO JUNIOR, D.; VITOR, C. M. T.; MORAIS, R. V.; MISTURA, C.; REIS, G. C. MARTUSCELLO, J. A. Acúmulo de forragem em pastos de Bracbiaria decumbens adubados com nitrogênio. Pesquisa Agropecuária Brasileira, Brasília, v. 40, n. 4, p. 397-403, 2005 a

DOI: http://dx.doi.org/10.1590/S0100-204X2005000400012

FAGUNDES, J. L.; FONSECA, D. M.; MISTURA, C.; MORAIS, R. V.; VITOR, C. M. T.; GOMIDE, J. A.; NASCIMENTO JUNIOR, D.; CASAGRANDE, D. R.; COSTA, L. T. Características morfogênicas e estruturais do capim-braquiária em pastagem adubada com nitrogênio avaliadas nas quatro estações do ano. Revista Brasileira de Zootecnia, Viçosa, v. 35, n. 1, p. 21-29, 2006. DOI: http://dx.doi.org/10.1590/S151635982006000100003

FAGUNDES, J. L.; FONSECA, D. M.; MISTURA, C.; MORAIS, R. V.; VITOR, C. M. T.; REIS, G. C.; CASAGRANDE, D. R.; SANTOS, M. E. R. Índice de área foliar, densidade de perfilhos e acúmulo de forragem em pastagem de capim-braquiária adubada com nitrogênio. Boletim de Industria Animal, Nova Odessa, v. 62, n. 2, p. 125-133, 2005 b.

FAGUNDES, J. L.; MOREIRA, A. L.; FREITAS, A. W. P.; ZONTA, A.; HENRICHS, R.; ROCHA, F. C.; BACKES, A. A.; VIEIRA, J. S. Capacidade de suporte de pastagens de capim-tifton 85 adubado com nitrogênio manejadas em lotação contínua com ovinos. Revista Brasileira de Zootecnia, Viçosa, v. 40, n. 12, p. 26512657, 2011. DOI: http://dx.doi.org/10.1590/S151635982011001200006

FLORES, R. S.; EUCLIDES, V. P. B.; ABRÃO, M. P. C.; GALBEIRO, S.; DIFANTE, G. S.; BARBOSA, R. A. Desempenho animal, produção de forragem e características estruturais dos capins marandu e xaraés submetidos a intensidades de pastejo. Revista Brasileira de Zootecnia, Viçosa, v. 37, n. 8, p. 1355-1365, 2008. DOI: $\quad$ http://dx.doi.org/10.1590/S151635982008000800004

HOFFMANN, A.; MORAES, E. H. B. K.; MOUSQUER, C. J.; SIMONI, T. A.; JUNIOR GOMES, F.; FERREIRA, V. B.; SILVA, H. M. Produção de bovinos de corte no sistema de pasto-suplemento no período seco. Nativa, Sinop, v. 2, n. 2, p. 119-130, 2014. DOI: http://dx.doi.org/10.14583/2318-7670.v02n02a10

IBGE_INSTITUTO BRASILEIRO DE GEOGRAFIA E ESTATÍSTICA. Censo agropecuário Brasileiro 2017. $2018 . \quad$ Disponível em: <https://censoagro2017.ibge.gov.br/templates/censo_ agro/resultadosagro/estabelecimentos.html?localidade $=$ $0>$. Acesso em 22 mar 2019.

MATA, J. F.; DOTTO, M. C.; ERASMO, E. A. L.; SIEBENEICHLER, S. C.; SANTOS, G. R.; BIANCO, S. Crescimento da Brachiaria brizantha cv. Piatã consorciada com a cultura da soja sob diferentes densidades e épocas de semeadura. Revista agroambiente online, Boa Vista, v. 8, n. 3, p. 377-386, 2014.

MEDEIROS, L. T.; REZENDE, A. V.; VIEIRA, P. F.; CUNHA NETO, F. R.; VALERIANO, A. R.; CASALI, A. O.; GASTALDELLO JUNIOR, A. L. Produção e qualidade da forragem de capim marandufertiirrigada com dejetos líquidos de suínos. Revista Brasileira de Zootecnia, Viçosa, v. 36, n. 2, p. 309-318, 2007. DOI: http:/ /dx.doi.org/10.1590/S1516-35982007000200006

PORTO, E. M. V.; ALVES, D. D.; VITOR, C. M. T.; SILVA, M. F.; MAGALHÃES, C. G.; DAVID, A. M. S. S.; GOMES, V. M.; BRANT, C. J. A. Produção de biomassa de cultivares do capim buffel submetidos à adubação nitrogenada. Revista Unimontes Científica, Montes Claros, v. 19, n. 1, p. 122-129, 2017.

QUATRIN, M. P. OLIVO, C. J.; AGNOLIN, C. A.; MACHADO, P. R.; NUNES, J. S.; CORREA, M. R.; RODRIGUES, P. F.; BRATZ, V. F.; SIMONETTI, G. D. Efeito da adubação nitrogenada na produção de forragem, teor de proteína bruta e taxa de lotação em pastagens de azevém. Boletim de Indústria Animal, São Paulo, v. 72, n. 1, p. 21-26, 2015. DOI: http://dx.doi.org/10.17523/bia.v72n1p21

RAIJ, B. V.; CANTARELLA, H.; QUAGGIO, J. A.; FURLANI, A. M. C. 1996. Recomendações de 
adubação e calagem para o Estado de São Paulo. 2.ed. Campinas: IAC. 285 p. (Boletim Técnico, 100).

ROCHA, G. O.; CHIZZOTTI, F. H. M.; SANTOS, M. E. R.; SOUSA, B. M. L.; FONSECA, D. M. Perfilhamento do capim-piatã submetido a regimes de desfolhação intermitentes. Arquivo Brasileiro de Medicina Veterinária e Zootecnia, Belo Horizonte, v. 71, n. 6, p. 2057-2064, 2019.2 DOI: http://dx.doi.org/10.1590/1678-4162-10373

SALES, E. C. J.; REIS, S.T.; MONÇÃO, F. P.; ANTUNES, A. P. S.; OLIVEIRA, E. R.; MATOS, V. M.; CÔRREA, M. M.; DELVAUX, A. S. Produção de biomassa de capim-marandu submetido a doses de nitrogênio em dois períodos do ano. Revista Agrarian, Grandes Dourados, v. 6, n. 22, p. 486-499, 2013.

SANTOS, L. C.; BONOMO, P.; SILVA, C. C. F.; PIRES, A. J. V. P.; VELOSO, C. M.; PATÊS, N. M. S. Produção e composição química da Brachiaria brizantha e Brachiaria decumbems submetidas a diferentes adubações. Ciência Animal Brasileira, Goiânia, v. 9, n. 4, p. 856-866, 2008.

SANTOS, H. G.; JACOMINE, P. K. T.; ANJOS, L. H. C.; OLIVEIRA, V. A.; LUMBRERAS, J. F.; COELHO, M. R.; ALMEIDA, J. A.; CUNHA, T. J. F.; OLIVEIRA, J. B. Sistema Brasileiro de Classificação de Solos. 3. ed, Brasília: Embrapa, 2013. 353 p.

SILVA, V. L. Produção de forragem e desempenho de vacas leiteiras em pastagem de Brachiaria brizantha cv. Marandu sob doses crescentes de adubação nitrogenada. 2015. 89f. Tese (Doutorado em Zootecnia) - Universidade Estadual do Sudoeste da Bahia, 2015. Disponível em: <http://www2.uesb.br/ppg/ppz/wpcontent/uploads/2017/07/Tese-Vinicius-Lopes-daSilva.pdf>. Acesso em: 23 mar. 2018.

VITOR, C. M. T.; FONSECA, D. M.; CÓSER, A. C.; MARTINS, C. E.; NASCIMENTO JÚNIOR, D.; RIBEIRO JÚNIOR, J. I. Produção de matéria seca e valor nutritivo de pastagem de capim-elefante sob irrigação e adubação nitrogenada. Revista Brasileira de Zootecnia, Viçosa, v. 38, n. 3, p. 435-442, 2009. DOI: http://dx.doi.org/10.1590/S1516-35982009000300006 